\title{
The Structure Optimization of Test-Bed for Load Bearing Performance of Harmonic Gear Drive
}

\author{
H. Feng, L. Zu, Y. Zhang, Y. Ou, Y. Liang, and J. Han
}

\begin{abstract}
This paper aims at the structural design and optimization of the test-bed for the load bearing performance of the harmonic gear drive. Based on the computer software, the mode analyses are given to the test-bed. The effects brought by different structures of stiffened plate on bed natural frequencies and deformations are studied. The Loading and overloading tests of the harmonic gear drive can be realized on the optimized designed test-bed, we can know the bearing capacity and transmission efficiency of the harmonic gear drive.
\end{abstract}

\section{Index Terms - Harmonic gear, test-bed, optimized design.}

\section{INTRODUCTION}

Harmonic gear drive is a kind of transmission device with high performance and precision, which has a good bearing capacity [1]-[3]. It is often used in aerospace aircraft and servo mechanism, operating mechanism and data transmission device of spatial intelligence machinery. Also in the general machinery field, harmonic gear drive becomes more and more popular. Researchers analyzed the loading conditions of the flexible and rigid wheels in the harmonic drive device on the basis of experimental and theoretical calculations. The references [4], [5] show the analysis and research of the stress on the load-carrying flexspline and the load distribution of the meshing parts. The reference [6] shows the mathematical model of the flexspline by the finite element. The reference [7] shows finite element method used to analyze the stress distribution of the flexspline with an opening at the cup bottom. It also presents a method to improve the bearing capacity by adapting the continuous variable thickness of cup bottom. The reference [8] shows a finite element method based on the contact problem on the basis of analyzing the existing research of flexspline strength. The numerical analysis model for the contact of flexspline and wave generator is established. The above research mainly based on theoretical analysis and finite element calculation. For the measurement of bearing performance of harmonic gear drive, there are no unified equipments in the domestic. The current testing methods and equipments are lagging behind. The testing processes cost too much time and labor, and are easily affected by man-made factors. So a test-bed for bearing performance measurement of harmonic gear drive is designed in this paper, it can achieve the loading and

Manuscript received December 2, 2014; revised August 23, 2015. This work was supported by the National Natural Science Foundation of China (51105206), also supported by the National Science and Technology Major Project of the Ministry of Science and Technology of China (2012ZX04002021).

The authors are with Nanjing University of Science and Technology, Nan Jing, Jiang Su Province, China (e-mail: fenght@njust.edu.cn, zuli@njust.edu.cn). overloading operation and related tests for harmonic gear drive. This paper focuses on the design of the loading test-bed, and does some modal pattern analysis based on the computer software; finally the optimization of the bed structure is given.

\section{MeAsurement PRINCIPLE OF LOAD BEARING TEST-BeD FOR HARMONIC GEAR DRIVE}

Load bearing performance test-bed can provide a platform for harmonic gear to run with loading or overloading, and operate the test of bearing torque. The test platform includes a torque speed sensor and measuring instrument, the loader and its controller, motor, coupling and so on. The block diagram of the measurement principle is as shown in the Fig. 1.

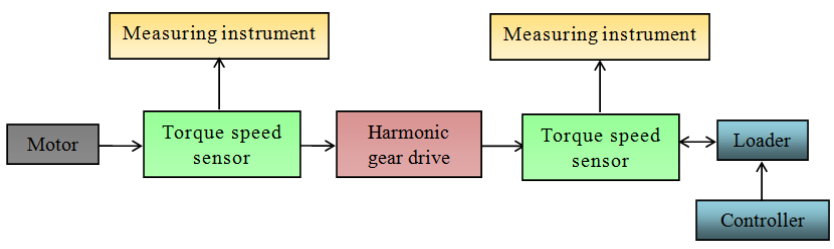

Fig. 1. Block diagram of the measurement principle.

The harmonic gear reducer is to be measured. Both the input and output ends are respectively connected with a torque speed sensor, function of the sensor is to transform the physical signals about torque and speed into electrical signals which can be gauged. After the signal amplification, interference shielding and data processing by using the measuring instrument, values of torque and rotational speed can be gained finally. The torque speed sensor connected with the output end of harmonic reducer is also connected to a loader. It transforms load force into load torque, which is controlled by the controller so as to meet the testing requirements of harmonic reducer's different load bearing capacity under different load. The torque speed sensor connected with the input terminal of harmonic reducer is connected to the motor with adjustable speed, which drives the whole test system. The test-bed can realize the tests of harmonic gear's bearing capacity and transmission efficiency under different speed and different load torque.

\section{Design OF THE TEST-Bed BENCH}

The material of the test-bed bench is HT250, which has a good casting property to cast many complex shapes, and also has some mechanical properties and shock absorption. The front of the bed is fitted with a motor and torque speed sensor, so the front needs to be raised in order to facilitate the grinding of the processing surface. All the processing 
surfaces need the grinding wheel to sweep completely. As for the front- convex-bed, the grinding wheel cannot sweep completely over the surface which is to be processed. Therefore, the motor and the torque speed sensor are set to a specified height so that the mounting surface of front seat can be lower, which is convenient for grinding wheel to process. As shown in Fig. 2.



Fig. 2. Front-sunken-bed.

The function of the bed is to bear components of the test bench. Some of components are are fixed, such as the front seat, some have reciprocating motions, such as the working table. So the requirements for the bed are that the bed can bear the static load and not generate larger deformation, and it has the higher resonance frequency with good anti vibration performance. On the other hand, lighter bed weight should be paid more attention to the design of the test-bed bench when meeting the above requirements. The function and the weight contradict each other. Reducing the weight needs to dig up the bed material, which can cut down the the function performance of the bed. Optimization design of stiffened plate will be important for the bed.

There are three typical structures of stiffened plate for test-bed bench: the transverse, the longitudinal and the oblique ribs. The transverse stiffened plate is shown in Fig. 3, which can improve the torsion stiffness of test-bed bench. The longitudinal stiffened plate is shown in Fig. 4, which can improve the bending stiffness of bed. The oblique stiffened plate is shown in Fig. 5, which can improve both torsion and bending stiffness.

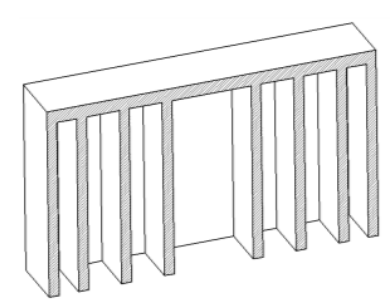

Fig. 3. Transverse stiffened plate.

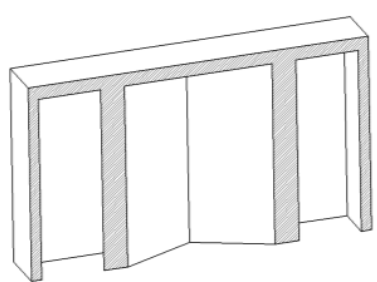

Fig. 5. Oblique stiffened plate.

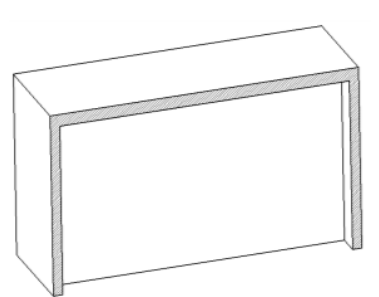

Fig. 4. Longitudinal stiffened plate.



Fig. 6. The arrangement scheme about the ribs.
Because the bed has a narrow width, only one longitudinal ribbed plate need to be designed. The bed is made in the mixed form of the oblique ribs and the transverse bar plate. At the same time one transverse rib is added to the bearing part of front seat to improve bed stiffness. Thickness of all stiffened plate is designed to be $16 \mathrm{~mm}$. The arrangement scheme of the stiffened plate for the bed bench is shown in Fig. 6.
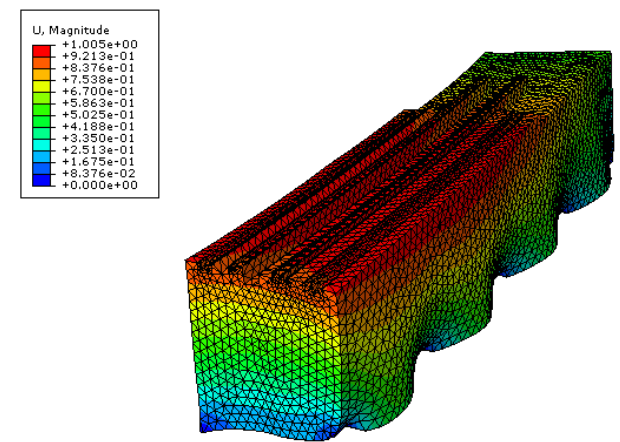

(a) The first vibration mode

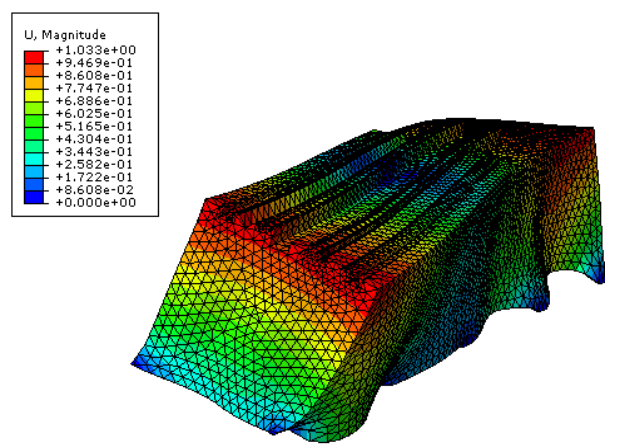

(b) The second vibration mode
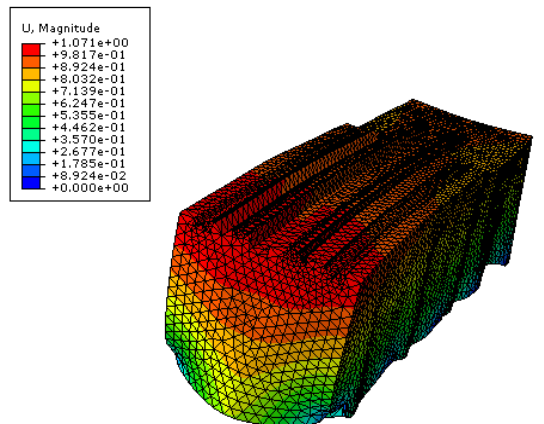

(c) The third vibration mode

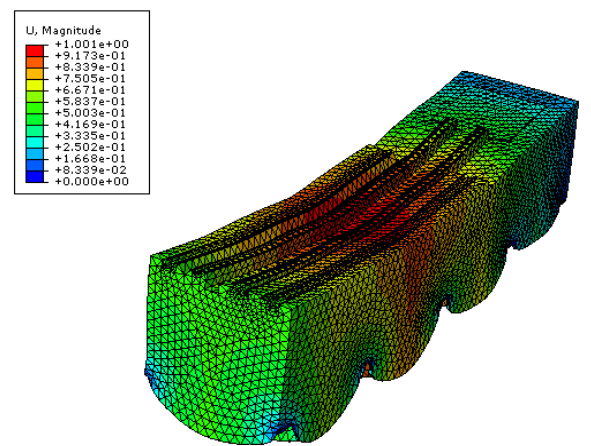

(d) The forth vibration mode

Fig. 7. Vibration modes of the bed.

The purpose of the test-bed bench is for the loading operation and test. The speed of motor is up to $6000 \mathrm{r} / \mathrm{min}$. So the excitation frequency will be higher. In the design the natural frequency of the bed body needs to be increased in order to improve its anti vibration performance. Now do the modal analysis for the bed bench. Firstly, using three-dimensional drawing software PROE for modeling, and then exporting model with IGES format into the finite element analysis software called Abaqus for analysis. In 
order to reduce the calculation time and avoid mistakes of meshing, the sharp parts of the bed including threaded holes and the pin holes need to be removed when deriving the mode. Because the test bench is leveled by padding irons when installing, so the boundary constraints on mounting surfaces of 10 padding irons should be added at the bottom of the bed. Analysis of the first four natural frequencies of the bed with the designed structure are carried out. Their vibration modes are shown in Fig. 7. The natural frequencies and the maximum deformation values are shown in Table I.

\begin{tabular}{|c|c|c|}
\hline & Natural frequency $(\mathrm{Hz})$ & $\begin{array}{c}\text { The maximum } \\
\text { displacement }(\mathrm{mm})\end{array}$ \\
\hline First Order & 192.45 & 1.028 \\
\hline Second Order & 265.98 & 1.070 \\
\hline Third Order & 269.66 & 1.071 \\
\hline Forth Order & 367.06 & 1.001 \\
\hline
\end{tabular}

TABLE II: THE NATURAL FREQUENCIES AND THE MAXIMUM DEFORMATION VALUES OF THE OPTIMIZED BED

\begin{tabular}{lcc}
\multicolumn{2}{c}{ DEFORMATION VALUES OF THE OPTIMIZED BED } \\
\hline \hline Natural frequency $(\mathrm{Hz})$ & $\begin{array}{c}\text { The maximum } \\
\text { displacement }(\mathrm{mm})\end{array}$ \\
\hline First Order & 238.41 & 1.005 \\
Second Order & 314.84 & 1.003 \\
Third Order & 327.10 & 1.045 \\
Forth Order & 414.34 & 1.001 \\
\hline \hline
\end{tabular}

The motor's rated speed is $6000 \mathrm{r} / \mathrm{min}$, the generated vibration frequency of the bed is maximum for $100 \mathrm{~Hz}$. However, the natural frequency of the first order vibration is only $192.45 \mathrm{~Hz}$, which is less than two times vibration frequency of the test bench. So the design margin is insufficient.

\section{Optimization Design of The Test-Bed BenCH}

The machined surfaces of the bed are matched with installation components, and the size parameters have been determined. So that the optimization of the teat-bed bench mainly concentrates on the ribs design. From the different vibration modes, we can see that more torsions are generated on the bed after excitation, especially in the third order resonance deformation. So optimization design on the original scheme is needed. Adding some transverse rib plates to the bed as shown in Fig. 8. In addition, 10 padding irons are used to support for the bed rather than fixing the bed bottom with the base together, a larger deformation will happen to the bottom of the bed after excitation, especially the part in contact with the padding irons, so a rib plate is required to strengthen the rigidity of the bed bottom as shown in Fig. 9. Since the bed is formed by casting, which needs auxiliary holes on the bottom plate for convenient casting.

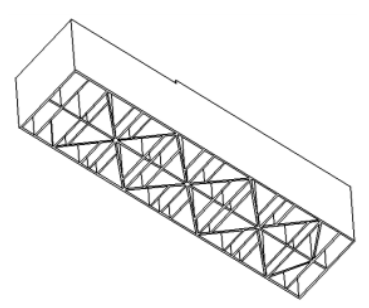

Fig. 8. Optimization of bed by adding some transverse rib plates.

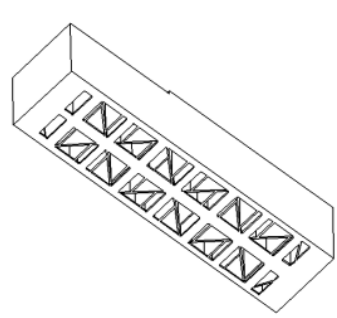

Fig. 9. Optimization of bed by adding a bottom rib plate.
Modal analysis of the optimized bed are given as shown in Fig. 10. the natural frequencies and the maximum deformation values are shown in Table II.

Now we can see that: after adding the transverse bar plates and the bottom plate, the natural frequencies of the bed is significantly improved, the first order frequency reaches $238.41 \mathrm{~Hz}$, which is two times more than the excitation frequency of $100 \mathrm{~Hz}$. The design is sufficient. Besides, the maximum deformation value is decreased. Finally the optimized test-bed bench structure is adopted in practice.

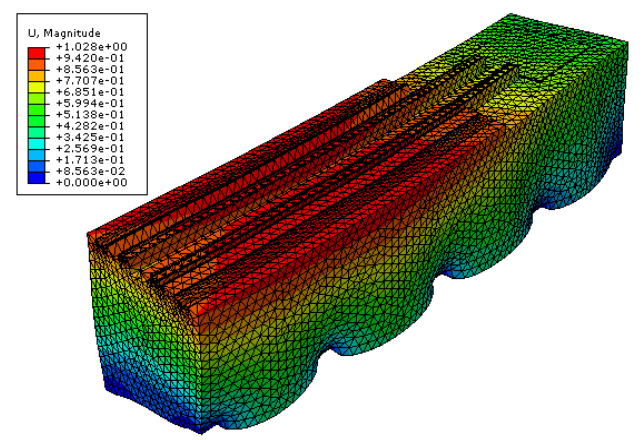

(a) The first vibration mode of optimized bed



(b) The second vibration mode of optimized bed

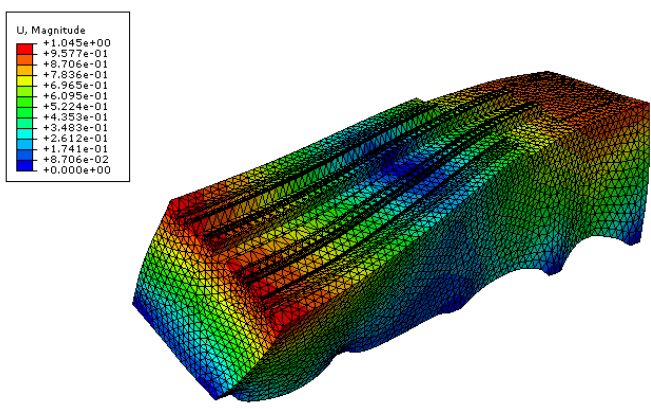

(c) The third vibration mode of optimized bed

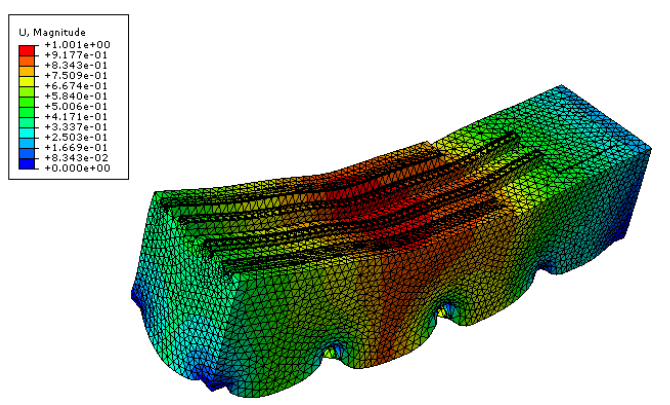

(d) The fourth vibration mode of optimized bed Fig. 10. Vibration modes of the optimized bed.

\section{CONCLUSION}

This paper presents the design of a test-bed bench for bearing performance measurement of harmonic gear. The loading and overloading tests of the harmonic gear drive can 
be realized. This paper discusses the test principle and achieves the structure design of the test-bed bench. The paper focuses on the optimization design of the rib structures. Based on the computer software, some modal analyses of the bed body are made. By the computer simulation and the comparisons, it is proved that the optimized test-bed bench structure can effectively improve the dynamic performance of bed, which ensures the reliability and safety of the test-bed.

\section{REFERENCES}

[1] M. Yamamoto, M. Iwasaki, M. Kainuma, Y. Okitsu, K. Yuki, K.Sasaki, and T. Yajima, "Compensation for Synchronous Component of Angular Transmission Errors in Harmonic Drive Gearings," in Proc. 2010 11th IEEE International Workshop on Advanced Motion Control, 2010, pp. 361-365.

[2] M. R Johnson, R. Gehling and R. Head. "Failure of Harmonic Gears During Verification of a Two-Axis Gimbal for the Mars Reconnaissance Orbiter Spacecraft," in Proc. 38th Aerospace Mechanisms Symposium, Langley Research Center, pp. 37-51, May 17- 19, 2006

[3] J. Rens, R. Clark, S. CaIverley, K. Atallah, and D. Howe. "Design, Analysis and Realization of a Novel Magnetic Harmonic Gear," in Proc. 2008 International Conference on Electrical Machines, 2008, pp. 1-7.

[4] W. Wang, H. Xin, and Z. Xu, "Finite element analysis of flexspline in harmonic gear drive," Journal of Beijing Technology and Business University:Natural Science Edition, vol. 25,no. 4, pp. 26-28, 2007.

[5] P. Yang, C. Wang, C. Wang, and L. Zhang, "Study on the preliminary deformation force of the flexspline in harmonic gear driving," Journal of Mechanical Strength, vol. 28, no. 1, pp.78-82, 2006.

[6] R. Krisch, "Investigation of the Meshing Condition of a Flat Wheel Harmonic Gear Drive," in Proc. the ASME 2007 International Design Engineering Technical Conferences \& Computers and Information in Engineering Conference I, DETC/CIE 2007, pp. 1-4, Las Vegas, Nevada, USA. September 4-7, 2007.

[7] M. Luo and Q. Zhang, "Analysis of Assembly Process of Flexible Gear Based on ABAQUS," Machine Building and Automation, vol. 41, no. 1, pp. 36-37, 2012.

[8] Shi Wei, Zhang Qing, and Li Xing, "The research about deformation and stress of flexspline in harmonic drive based on ABAQUS," Mechanical Engineer, no. 6, pp. 44-47, 2010.

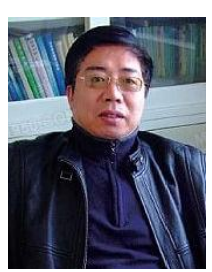

Hutian Feng was born in Jinzhou, China on January 21 1965. In July 1986, Feng Hutian received the bachelor's degree in Zhongbei University, China in mechanical engineering. In March 1991, Hutian Feng received the master's degree in Nanjing University of Science and Technology, China in mechanical engineering. In September 2000, Hutian Feng received the doctor's degree in Nanjing University of Science and Technology, China in mechanics.

His research concerned multi-functional moving robot and mechatronic measurement and control technology. He now is in charge of a national key science and technology project: research of rolling components in high-end cnc machine tool. He is also the vice-dean of Mechanical and Electronic Engineering Department, Nanjing, China

Dr. Feng is a member of Chinese Mechanical Engineering Society.

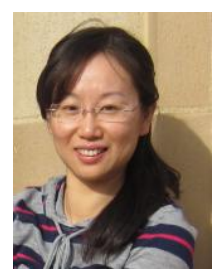

Li Zu was born in Nanjing, Jiangsu Province, China on June 19, 1977. In July 1999, she received the bachelor's degree in Suzhou University, Su Zhou Jiang Su Province, China in mechanical design and theory. In July 2005, she received the doctor's degree in Nanjing University of Science and Technology, Nanjing, Jiangsu Province, China in mechanical and electronic Engineering.

She has worked in Nanjing University of Science and Technology as a teacher for 9 years from July 2005. Now she is an associate professor in the Dept. of Mechanical Design and Automation. From August 2012 to January 2013, She was a visiting scholar in California State University, Northridge, USA. Now she is working on National Natural Science Foundation Project - "Studies of the Load-bearing Performance of Precision Harmonic Gear within Abnormal Conditions and Design" and National Science and Technology Major Project - "Common Technology of Rolling Elements in the CNC Machine and Testing, Test Equipment
Development Platform”. She has published 1) L. Zu, L. Zhang, and H. k. Wang, "Optimization design of the lawn mowing vehicle's blade based on aerodynamics," Advanced Materials Research, pp. 231-237, 2011. 2) L. Zu, Y. Liang, and M. L. Song, "Study and design of an inchworm-1ike micro-robot walking mechanism," Lecture Notes in Electrical Engineering vol. 123, pp. 69-78, 2011. Her research area covers mechanical design, precision drive technology and intelligent machines.

Prof. $\mathrm{Zu}$ is a member of the Association of Mechanical Engineering of Nanjing, Jiang Su Province, China.

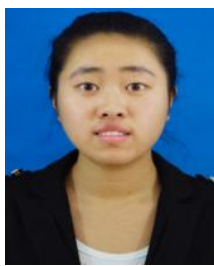

Yiwen Zhang was born in Wu Xi, Jiang Su Province, China on February 27, 1992.

In July 2014, she received the bachelor's degree in Nanjing University of Science and Technology, Nan Jing, Jiang $\mathrm{Su}$ Province, China in mechanical engineering and automation. And she has been studied in Nanjing University of Science and Technology as a master since July 2014. She is working on the test beds of the roller linear guide and ball screw.

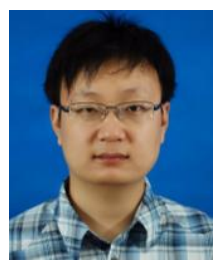

Yi Ou was born in Shaanxi, P. R. China, on August 28, 1982. Yi Ou earned his bachelor's and master's degree of mechanical engineering in Nanjing University of Science and Technology, Jiangsu province, P.R. China, in 2006 and 2012, respectively.

He has been teaching and researching in the field of dynamic performance analysis, precision test and life/reliability analysis for function units of machine tools, especially the rolling components combined with rigid-flexible coupling multi-body mechanical theory, contact mechanics, etc., dynamic performance analysis and optimization design for rolling components are carried out. The research results are embedded in the related national key scientific research project. His major field of study is mechanical design, Ground mobile robot technology, Measurement and control technology of mechanical system.

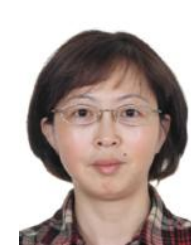

Yi Liang was born in Shaanxi, P.R. China, on August 5 , 1974. Yi Liang earned her bachelor and master's degrees of mechanical engineering in Nanjing University of Science and Technology, Jiangsu province, P.R. China, in 1991 and 1998, respectively. Her major field of study is mechanical design and optimization.

She has been teaching and researching in the field of mechanical engineering since 1998 in Nanjing University of Science and Technology. The courses she taught are mechanisms and machine theory, machine elements, and mechanical optimization for the undergraduates and postgraduates. Associate professor Yi Liang focuses on the research of mechanical design and finite element analysis of machine elements. Two of her published articles are listed here: "Transmission momentary efficiency based on the $\mathrm{D}$ “Alembert -Lagrange equation for involutes gear," Chinese Journal of Mechanical Engineering, vol. 2, pp. 272-275, Dec. 2004; "Finite element analysis of shell of mower cutter head," Journal of Machine Design, vol. 21, pp. 253-254, Jun. 2005. Now Yi is interested in the optimization design and accuracy analysis of rolling linear guide ways.

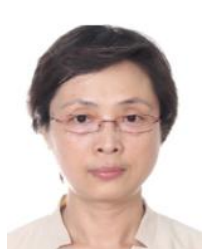

Jun Han was born in Hebei, China, on August 5, 1963. Jun Han earned her bachelor's and master's degree of mechanical engineering in Nanjing University of Science and Technology, Jiangsu province, China, in 1985 and 1994, respectively.

She has been teaching and researching in the field of mechanical engineering since 1985 in Nanjing University of Science and Technology. The courses she taught are introduction to control engineering and fundamentals of robotics, fundamentals of machine and electricity transmission and control for the undergraduates. As an associate professor, she focuses on the research of precision detection and control, and robot control technology. Two of her published articles are listed here: "Development of the experiment system of kinematics of 6R Robot," Laboratory Research and Exploration, vol. 22, pp. 103-104, 133, Jun. 2003, "Model study of precision loss of linear ball guides," Modular Machine Tool \& Automatic Manufacturing Technique, vol. 12, pp. 33-36, Jun. 2013, One of her published book is listed here: Comprehensive Performance Measurement Methods and Technology for Ball Screw Pair, China Machine Press, April 2011, pp. 127-174. Her major field of study is precision detection and control and robot control.

Ms. Han joined the membership in China Electro Technical Society. 